\title{
A Comprehensive Study Of The Perceptions And Support Structures Of Women Engaged In IT/IS Careers
}

Peter Draus, Robert Morris University, USA Sushma Mishra, Robert Morris University, USA Natalya Goreva, Robert Morris University, USA Donald Caputo, Robert Morris University, USA Gregory Leone, Robert Morris University, USA Diana Repack, USA

\begin{abstract}
Women engaged in the Information Technology/Information Systems (IT/IS) sphere of the American collegiate and corporate experience have made significant strides in employment and opportunities for advancement culminating in the recent achievement of women reaching the CEO and presidential levels of the largest corporations in the IT sphere. Despite this significant and welcomed departure from past experiences, the progression of women matriculating in the university IT/IS major, and following through to the career phase has not materialized in numbers that equal the proliferation of male entrants. This research study relates to the factors that have the most influence on the perceptions, constraints and positive experiences leading to the choice of career development at the collegiate level. The specific areas that will be investigated and tabulated within this context are that of role models, mentoring, pre-college perceptions, and equal opportunity considerations.
\end{abstract}

Keywords: Women in Information Technology; Mentoring; Exposure to IT; Statistical Analysis

\section{INTRODUCTION}

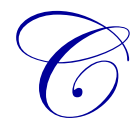

omputing degree programs and subsequent career opportunities point to an acute shortage of women participants. Even though the number of women earning college degrees is on the rise, women earning computing degrees in universities throughout the nation, and eventually entering the work force in computing related jobs in the United States are severely underrepresented. In 2003 and 2004 in the United States, male students who earned bachelor degrees in information sciences and computing outnumbered females by nearly 3 to 1 (U.S. Department of Education, 2005). Conversely, more women are enrolling in and completing their college education than men.

This decreasing number of women in the field clearly contributes to the overall gap between the supply of, and demand for, IT professionals (Sauter, 2012). This reduced representation of women can also mean skewed understanding of how IT responds to the needs of businesses and society. For example, both the disproportionately large number of men and their seniority in the IT sector foster a bias toward male viewpoints dictating product development, the process of development, the design of new technology, and, ultimately, the relative usefulness of new technology to all users (Sauter, 2012, Mishra et al, 2013). Some research suggests that increasing the number of women in development teams can contribute to improved success in design and management of IT projects (Sauter, 2013). Does this lack of participation/diversity signal a serious national educational problem? Certainly, the computing and information technology field is missing the additional talent and perspective that women bring into the work force (Balcita et al., 2002). Additionally, even the individual woman is missing out on career advancements and job opportunities which are available in computing related fields. Considering that IT work is well-compensated and rewarding, this gender inequality in this particular field has long term socio-economic implications. 
Research literature in this area of gender gap in IT careers shows how different social and policy support structures open the doors for female career success. However, the topic of how to support women at work is complex (Gutherie et al., 2009). In this study we have tried to capture the aspirations and underlying social factors that attract women to male dominated careers such as information technology. Previous research suggests that women's choice of IT as a major and as a career is dependent on the role of mentors in their career choice, exposure to IS/IT courses early on in middle and high school and the working environment providing equal opportunities. This study focuses on these parameters leading to paucity of women in IT careers.

The research questions posed in this study are:

RQ1: How important is mentoring for women in choosing a career in IS/IT?

RQ2: What roles do exposure to IS/IT concepts, early on in K through 12, have on the choices of women?

RQ3: What are the perceptions of women on equal opportunities in work-related IT fields?

The remainder of the paper is organized with the initial section as a review of relevant research literature in the area of women in information technology careers. The literature review section is followed by the results section that discusses the data collection and data analysis steps performed for this study. The test results are presented and explained in the context of the study. After presenting the results of the analysis, the discussion section establishes the significance of the results of this study, both in terms of further research and useful findings for the practitioner. The contributions and limitations are presented and major conclusions drawn.

\section{LITERATURE REVIEW}

This section presents a critical review of the research in the area of women in information technology, computing curriculum and technology fields as career options. Before we delve into the research studies in this area, we need to establish the definition of computing, computing courses, and what it means to have a job or career in the computing field. Computing courses are those which involves specific training on the artifacts, operations, and usages of computing (Mishra et al., 2013) .They include but are not limited to courses in software, hardware, systems development, security of information, database development, networking, programming, systems analysis, project management, or information management.

There have been several studies that explore the traits and image of information technology discipline as a major and also as a career. IT as a profession has been generally associated with masculine traits such as intellect, logic, scientific, and technical skills, whereas femininity is often associated with intuition, emotion, social/soft technical skills, and teamwork organization. This widely held perception of fields greatly impacts the allocation of skill labels, status, prestige, skill rewards, and organization of work in professions (Trauth \& Quesenberry, 2006). A review of the research in this domain suggests a number of reasons why women do not seek and/or why they do not stay in the IT field. One of the reasons proposed to explain why women do not pursue IT careers in the literature is the fear of stereotypes (Sauter, 2012, Mishra et al., 2013). "Stereotype threat," which is sometimes referred to as stereotype vulnerability, is a fear that one will be judged or treated in terms of a negative stereotype of one's group. It is experienced by individuals who generally are a minority in a field and who, as a group, are frequently reminded of their alleged ineptness in the field of study. When faced with a task, individuals experience anxiety to perform well (Sauter, 2012).

Women are not only reluctant to get into an IT career but also choose to move away to other career choices much more often than men do. Retention issues compound the lack of diversity in IT. Technology has the largest attrition rate at 56\% compared to 39\% for engineering and $47 \%$ for science which is almost double the rate of males (Fisher et al., 2013). While there are many reasons why women change direction, or leave their company, it is clear that in IT the retention of qualified women, already a scarce resource, is a major issue (Fisher et al., 2013).

It is suggested that IT workplaces, because they are male dominated, can be challenging environments for women resulting in women leaving to pursue other careers (Fisher et al., 2013; Mishra et al., 2013). Webb and Young (2005) suggest, that having a low number of women impacts on the workplace climate leading to a "dominant male culture." This results in discriminatory behavior and women having lower levels of influence 
(Ahuja, 2002). Due to this male dominated nature of the industry, these jobs offer fewer opportunities for promotion because of a lower recognition of women's work and skills, and creating unfriendly workplaces for women. Thus, we contend that such a climate impacts on women's participation and their employment outcomes (Ahuja, 2002; Fisher et al., 2013).

Several studies have concluded that even though IT jobs are described as interesting and challenging, IT professionals are often perceived as "geeks" or "nerds" who can relate to machines more than people (Zhang, 2007). The geeky image of IT professionals could negatively affect students' attitude towards choosing an IS major. Gavin (1998) researched student's interest in mathematics and science among students with high ability for mathematics. He reported that the usefulness of mathematics courses was rated higher by the males than by the females. Having a positive attitude towards the usefulness of mathematics is an important factor in a women's choice in mathematics oriented careers (Gavin, 1998). This widely held belief that women are not strong in mathematics and technology and hence hesitate to pick information systems as a major led us to the research questions in this study. The following section presents the methodology section of this research.

\section{METHODOLOGY}

\section{Data Collection}

The survey designed for the purpose of this study included a number of questions related to the reasons for career choice, perception of equal opportunities in IT and mentoring, attitude to management, and other salient issues. After the survey was mailed to a sample of IT women professionals, we received 659 replies which were included in data analysis. While all responding women were employed in IT, only 294 had degrees in IT. Among the rest, 126 had other degrees and the remaining 233 respondents did not have college degrees. Shown in Figure 1 are the demographics of the respondents. The demographics included annual income, age, and the number of years spent at a current job. The majority of respondents, it is noted, spent 1-6 years at their jobs. The study showed that the least popular areas among women employed in IT were networking and programming, while the least objectionable fields were forensics and web development.

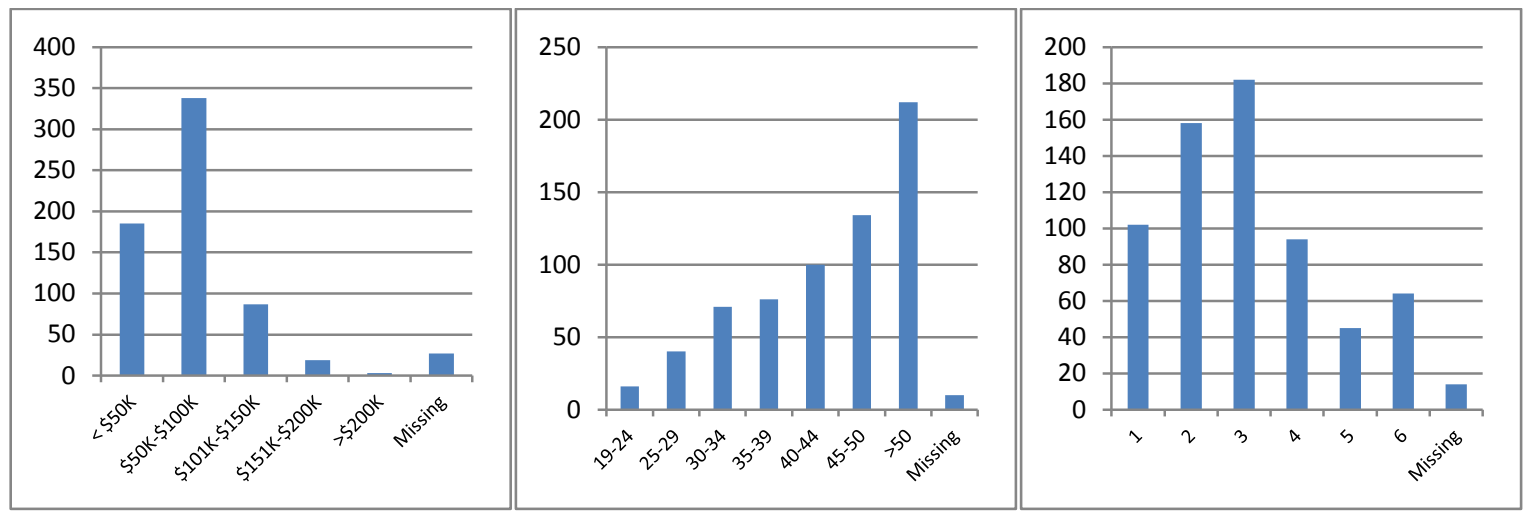

Figure 1: Respondents' Income, Age, and Years of Experience at Current Job

\section{Data Analysis}

RQ1: How important is mentoring for women in choosing a career in IS/IT?

In order to answer this question we looked at two aspects: first, how helpful mentoring is for the women who already chose a career in IT, and second, how important it is for those who are deciding about choosing a career in IT. There was no evidence of whether the women employed in IT considered mentoring to be an important factor in their career. In fact, a small negative correlation was found between the number of year the women have worked in the field and the perceived effect of mentoring. In other words women with more experience see less usefulness in mentoring. Another interesting finding, the amount of mentoring women do at their jobs, does not improve or 
worsen their attitude towards mentoring. There was no significant correlation found between the amount of mentoring women encountered and their perception of mentoring effectiveness.

As related to the second part of this question, over half $(57 \%)$ admitted that mentoring had little or no impact on their decision to pursue a career in IT. At the same time, a significant number (39\%) admitted that mentoring had some or high impact on their career choice.

RQ2: What roles do exposure to IS/IT concepts, early on in K12, have on choice of women?

Although we obtained the data that is helpful in answering this question, a more thorough research needs to be done to give a more accurate answer. Only half of the subjects had been exposed to computer courses in middle and high school, and another $25 \%$ had very little exposure. In college, however, more than half of the subjects had extensive course work in IT. We then suggested that more senior subjects may have had less exposure to IT in school or in college. When we drilled down and analyzed the correlation between age and exposure to IT; there was a strong negative correlation (-0.4) between age and exposure, meaning that older participants were less exposed to IT courses both in secondary school and in college. Interestingly, there was an almost zero correlation between age and college experience - subjects of all ages had roughly the same amount of IT exposure in college.

RQ3: What are the perceptions of women on equal opportunities in work IT field?

The first set of findings relates to the preferred environment and includes some interesting facts. When asked if they preferred female-dominated or male-dominated environments, as expected, most women replied that they did not see any difference. Surprisingly, the ones that did see the difference preferred a male-dominated environment. Overall, of all respondents who had preferences, $89 \%$ preferred working with men. When categorizing the participants by experience, we found out that the subjects who have less than 1 year of experience and who have gender-based preference would rather work in a female-dominated environment, while each category with more than 1 year of experience preferred a male-dominated environment. Similarly to this, the majority of respondents reported no preferences of the gender of their supervisor. The majority of the ones that indicated a preference would want a male supervisor. The exception again is the first category, that of women employed in IT with less than 1 year of experience. Finally, the subjects were asked whether they preferred a more social environment or remote (telecommuting) environment. The majority of respondents preferred the combination environment. Interestingly, the next most popular category was the social environment (16\%) and only $7 \%$ of the subjects preferred to work remotely.

Another set of questions was targeted at the women's perception of equal opportunities in the IT careers. No significant differences in opinion were found among the groups classified by experience. According to $67 \%$ of the subjects, the degree to which IT career opportunities are equal for men and women depended on the organization. Among the rest of the respondents who believed that there were no equal opportunities, the majority $(82 \%)$ felt women had less opportunities than men.
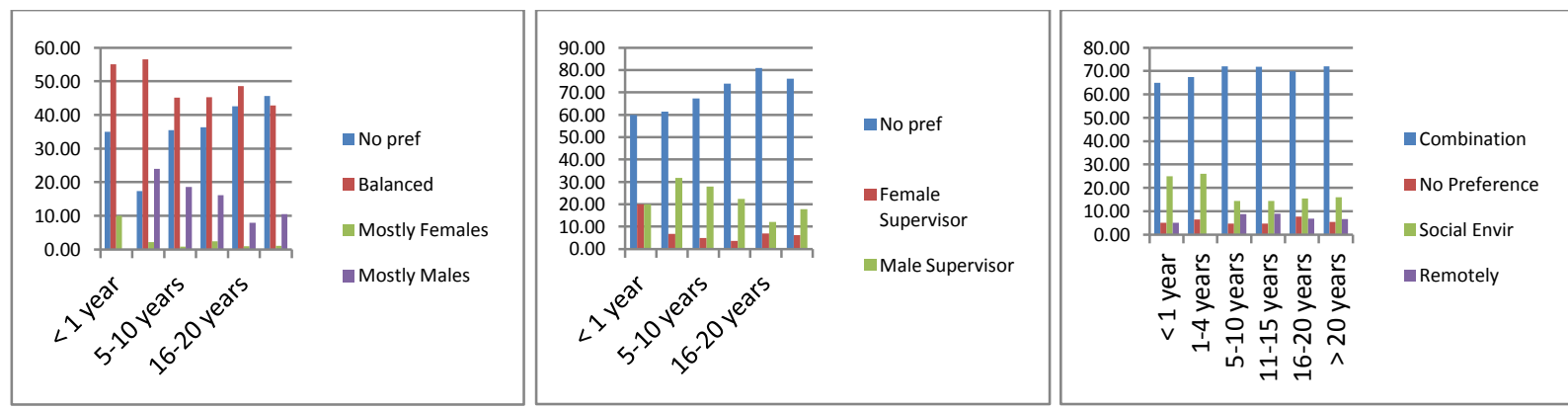

Figure 2: Work Environment Preference (\%) by Years Worked 


\section{DISCUSSION AND LIMITATIONS}

A sample of 695 professional women employed in IT was surveyed for this study. The subjects came from different educational backgrounds and different professional experiences, some having less than 1 year of experience in IT and some having over 20 years of experience. The study showed that half of the respondents admit that mentoring is useful. The perception of the usefulness of mentoring did not correlate with the amount of mentoring the subjects did. In other words, no matter how many years subjects were in the field, about the same percentage thought that mentoring was useful. In those women who did not believe in mentoring, it is possible that their lack of trust stemmed from the fact that few of them actually did mentoring. Over $75 \%$ of respondents mentored one or no women through their career.

The second research question caused a lot of uncertainty. It was impossible to correlate the amount of early IT exposure and the decision to pursue a career in IT, mainly because a majority of respondents with most experience in IT could not be exposed to it in school because there were no IT courses offered at that time. Finally, the majority of women perceive that it depends on the organization as to whether women have equal career opportunities as men. Of the ones who believed there are no equal opportunities, the majority thinks that it is easier for men to build a career in IT than for a woman.

Our findings are consistent with findings of other studies in this area. Few women worked in organizations with formal mentoring programs. Women from engineering, the Big-4 IT organizations and the insurance industry said the mentoring programs were ineffective because of lack of interest of the mentor and lack of a fit to the mentee's career (Gutherie et al., 2009). There is also an issue of what people perceive "mentoring" to be. The definition of mentor varied. Women found informal mentoring much more successful. Women earlier in their careers identified women as informal mentors. They self-selected women who were leaders in the organization as mentors, referring to the "strong woman" who was a role model (Gutherie et al., 2009).

This study contributes to current research in two ways. First, this study presents an interesting relationship between mentoring and career success for women in the computing field. Many studies in this area have suggested a positive impact of formal mentoring on the career of women working in the technology field, but our study suggests no such clear relationship. This relationship needs further investigation. Second, studies have proposed that early exposure to IS/IT concepts shapes women's career choices in the field of computing (Mishra et al., 2013). Our results suggest that the majority of women working in this field did not have much exposure to the concepts of computing during their education at the school or college level. We believe that this aspect of women in computing needs to addressed more seriously. The future research directions evident from this work are in investigating the role of mentoring in depth. Also, we need to further investigate if early exposure to IS/IT concepts plays any role at all in shaping the preferences of women towards technology related fields. This study is not without its limitations. The data that we collected through survey has self-report bias. We are accepting the choices made by participants as accurate. Also, we have exclusively surveyed women and have their perspective about the state of affairs for women in IT. We have not included the perspective of men about these issues which not only is critical to understand this whole issue but also crucial in solving the current shortage of women in the technology field.

The research literature stresses the importance of networking which, in many cases, is important for career progression. The reality is that women do not have time outside of work to participate in networking activities. Informal work networks could bridge that gap (Ahuja, 2002). The more women in an organization, the less discrimination is detected by the female workers. In summary, we can conclude that support structures (formal and informal) help women aspire to and maintain a technology career which is rewarding and offers opportunities for advancement.

\section{CONCLUSION}

This study explores the perception of women, who have a part in the information technology field, about role of: mentoring for successful IT career, exposure to IS/IT concepts early on in K-12 education and perceptions of women on equal opportunities in career IT fields. A survey of 695 working women in the field of information technology was conducted. Out results suggest that role of mentoring is not clearly defined in shaping the career of 
these working women. Many of these women did not have any exposure to IS/IT courses or concepts during their K12 education or even college. Implications were drawn and limitations presented. Future research stemming from this work is also discussed.

\section{AUTHOR INFORMATION}

Peter Draus, Robert Morris University, USA. E-mail: $\underline{\text { draus@ @rmu.edu }}$

Sushma Mishra, Robert Morris University, USA. E-mail: mishra@rmu.edu (Corresponding author)

Natalya Goreva, Robert Morris University, USA. E-mail: goreva@rmu.edu

Donald Caputo, Robert Morris University, USA. E-mail: caputo@rmu.edu

Gregory Leone, Robert Morris University, USA. E-mail: leone@ @rmu.edu

Diana Repack. E-mail: repack@ comcast.net

\section{REFERENCES}

1. Ahuja, A. (2002). Women in the information technology profession: A literature review, synthesis and research agenda. European Journal of Information Systems, 11, 20-34.

2. Balcita, A. M., Carver, D. L., \& Soffa, M. L. (2002). Shortchanging the future of information technology: The untapped resource. ACMSIGCSE Bulletin, 34(2), 32-35

3. Fisher, J., Lang, C., \& Annemieke, C. (2013). Women in the IT workplace: Lessons for managers. (ECIS 2013 Completed Research. Paper 34). Retrieved from http://aisel.aisnet.org/ecis2013_cr/34

4. Guthrie, R., Soe, L., \& Yakura, E. (2009). Support structures for women in information technology careers. AMCIS 2009 Proceedings. Paper 138. Retrieved from http://aisel.aisnet.org/amcis2009/138

5. Mishra, S., Draus, P., Caputo, D., Leone, J. Kohun, F., \& Reepack, D. (2013). A longitudinal study of enrollment trends and graduation GPAs for men and women in CIS programs. Issues of Information Systems.

6. Sauter, V. L. (2012). The absence of gender differences among students in an MIS program. Communications of the Association for Information Systems, 31(4). Retrieved from http://aisel.aisnet.org/cais/vol31/iss1/4

7. Trauth, E., \& Quesenberry, J. (2006). Are women an underserved community in the information technology profession? Twenty-Seventh International Conference on Information Systems, Milwaukee 2006.

8. U.S Department of Education, (2005). Women's educational equity. Retrieved 12/05/13 from http://www2.ed.gov/programs/equity/2005awards.html

9. Webb, P., \& Young, J. (2005). Perhaps it's time for a fresh approach to ICT gender research? Journal of Research and Practice in Information Technology, 37(2), 147-160. 